Research

\title{
Predictors of anti-convulsant treatment failure in children presenting with malaria and prolonged seizures in Kampala, Uganda
}

\author{
Arthur Mpimbaza*1, Sarah G Staedke ${ }^{2}$, Grace Ndeezi ${ }^{1}$, Justus Byarugaba ${ }^{1}$ and \\ Philip J Rosenthal ${ }^{3}$
}

Address: ${ }^{1}$ Department of Paediatrics and Child Health, Faculty of Medicine, Makerere University, Kampala, Uganda, ${ }^{2}$ London School of Hygiene and Tropical Medicine, London, UK and ${ }^{3}$ Department of Medicine, San Francisco General Hospital, University of California, San Francisco, California, USA

Email: Arthur Mpimbaza* - arthurwakg@yahoo.com; Sarah G Staedke - sarah.staedke@lshtm.ac.uk; Grace Ndeezi - gracendeezi@yahoo.com; Justus Byarugaba - byarugabaj@yahoo.com; Philip J Rosenthal - prosenthal@medsfgh.ucsf.edu

* Corresponding author

Published: 29 June 2009

Malaria Journal 2009, 8:145 doi:10.1/86/1475-2875-8-145
Received: 12 February 2009

Accepted: 29 June 2009

This article is available from: http://www.malariajournal.com/content/8/I/I45

(c) 2009 Mpimbaza et al; licensee BioMed Central Ltd.

This is an Open Access article distributed under the terms of the Creative Commons Attribution License (http://creativecommons.org/licenses/by/2.0), which permits unrestricted use, distribution, and reproduction in any medium, provided the original work is properly cited.

\begin{abstract}
Background: In endemic areas, falciparum malaria remains the leading cause of seizures in children presenting to emergency departments. In addition, seizures in malaria have been shown to increase morbidity and mortality in these patients. The management of seizures in malaria is sometimes complicated by the refractory nature of these seizures to readily available anticonvulsants. The objective of this study was to determine predictors of anti-convulsant treatment failure and seizure recurrence after initial control among children with malaria.

Methods: In a previous study, the efficacy and safety of buccal midazolam was compared to that of rectal diazepam in the treatment of prolonged seizures in children aged three months to 12 years in Kampala, Uganda. For this study, predictive models were used to determine risk factors for anticonvulsant treatment failure and seizure recurrence among the $22 \mathrm{I}$ of these children with malaria.
\end{abstract}

Results: Using predictive models, focal seizures (OR 3.2I; $95 \% \mathrm{Cl} \mathrm{I.42-7.25,} \mathrm{p}=0.005$ ), cerebral malaria (OR 2.43; 95\% Cl I.20-4.9I, $\mathrm{p}=0.0 \mathrm{I}$ ) and a blood sugar $\geq 200 \mathrm{mg} / \mathrm{dl}$ at presentation (OR 2.84; $95 \% \mathrm{Cl} \mathrm{I.II-7.20,} \mathrm{p}=0.02$ ) were independent predictors of treatment failure (seizure persistence beyond 10 minutes or recurrence within one hour of treatment). Predictors of seizure recurrence included: I) cerebral malaria (HR 3.32; 95\% Cl I.94-5.66, $\mathrm{p}<0.00 \mathrm{I}), 2$ ) presenting with multiple seizures (HR 2.45; 95\% Cl I.42-4.23, $\mathrm{P}=0.00 \mathrm{I}$ ), 3) focal seizures (HR 2.86; $95 \% \mathrm{Cl} \mathrm{I.49-}$ $5.49, \mathrm{p}=0.002), 4)$ recent use of diazepam $(\mathrm{HR} 2.43 ; 95 \% \mathrm{Cl} I .19-4.95, \mathrm{p}=0.0 \mathrm{I})$ and 5$)$ initial control of the seizure with diazepam (HR I.96; $95 \% \mathrm{Cl} \mathrm{I.16-3.33,} \mathrm{p}=0.01)$.

Conclusion: Specific predictors, including cerebral malaria, can identify patients with malaria at risk of anti-convulsant treatment failure and seizure recurrence. 


\section{Background}

In endemic areas, falciparum malaria remains the leading cause of seizures in children presenting to emergency departments [1-4]. In addition, seizures are the most common neurological complication of severe malaria, often resulting in hospital admission, and seizures have been shown to increase morbidity and mortality in these patients $[1,4,5]$. The management of seizures in malaria is complicated, as they may be refractory to readily available anti-convulsants and there is concern for drug induced respiratory depression [6].

Uncontrolled seizures in malaria can damage the brain by aggravating hypoxia, hypoglycaemia and intracranial hypertension, and in children with cerebral malaria they have been shown to increase the risks of neurological complications, cognitive impairment and death [5,7-10]. In addition, children with malaria and complicated seizures are at a significantly higher risk of developing epilepsy as compared to children without this complication [11].

Diazepam administered intravenously or rectally is the recommended first-line treatment for seizures in children with malaria $[6,12]$. However, use of diazepam is characterized by high failure rates, particularly with the rectal route of administration [13]. Even when seizures are controlled, relapse rates are high, probably due to the short duration of action of diazepam in the brain $[6,13]$. This limitation leads to repeated administration of diazepam, largely in settings where alternative safe and effective anticonvulsants are not available [14]. The key danger with repeated dosing of diazepam is respiratory depression $[13,15]$, an uncommon occurrence with appropriate dosing of the drug [16]. Furthermore, the use of phenobarbital, a readily available second-line agent, in addition to diazepam may increase the risk of respiratory depression [17]. A good therapeutic alternative to diazepam is midazolam, which unlike diazepam is water-soluble and can be administered through the buccal and nasal routes $[6,18,19]$. Midazolam has been shown to be at least as effective and safe as diazepam in the management of seizures in children in Europe and in Africa [4,20-23].

Identification of patients at risk of failing anti-convulsant treatment or experiencing recurrences of seizures after initial control is a practical step toward improving the care of children with malaria complicated by seizures. If identified early these children could be provided with optimal anti-convulsants to control seizures and minimize the risk of respiratory depression. In this study, risk factors for anti-convulsant treatment failure and seizure recurrence among Ugandan children with malaria and prolonged seizures were identified.

\section{Methods \\ Study design}

Results of a randomized trial to compare the efficacy and safety of buccal midazolam versus rectal diazepam in children with persistent seizures were reported previously [4]. The study was conducted between November 2005 and June 2006 in the Acute Care Unit (ACU), the paediatric emergency unit of Mulago Hospital, the national referral hospital in Kampala, Uganda. Patients were enrolled if they fulfilled the following criteria: (1) three months to 12 years of age, (2) no documented evidence of having received IV diazepam or IV phenobarbital within 24 hours prior to presentation, (3) documented seizure persisting for more than five minutes at the time of administration of study drug, and (4) provision of informed consent to continue participation in the study. In view of practical limitations, informed consent was waived upon emergency presentation. Written consent to continue participation in the study was subsequently sought from parents or legal guardians as soon as was practically possible after initial evaluation and treatment.

Patients were randomly assigned to one of two treatment arms: rectal diazepam and buccal placebo or rectal placebo and buccal midazolam. Parenteral preparations of both diazepam (Roche, France) and midazolam (Roche, France) were prepackaged by a pharmacist in two boxes that corresponded to the two treatment arms. Boxes were stored at $5-10^{\circ} \mathrm{C}$ and emptied and refilled on a weekly basis. Diazepam and placebo were packaged in $2 \mathrm{ml}$ glass syringes and buccal midazolam and placebo were packaged in $2 \mathrm{ml}$ plastic syringes. Both re-packaged midazolam and diazepam are stable under these conditions for up to one month [24-26]. Both drugs were administered at approximately $0.5 \mathrm{mg} / \mathrm{kg}(2.5 \mathrm{mg}$ for age 3 to 11 months; $5 \mathrm{mg}$ for age 1 to 4 years; $7.5 \mathrm{mg}$ for age 5 to 9 years; $10 \mathrm{mg}$ for age 10 to 12 years). The primary study outcome was cessation of visible seizure activity within 10 minutes of receiving study medications without recurrence in the subsequent one hour. If the seizure persisted beyond 10 minutes or recurred within one hour after initial control, the child was categorized as a treatment failure. Secondary outcome measures included: 1) proportion with cessation of convulsions within ten minutes, 2) proportion with seizure recurrence in subsequent hour and within 24 hours after initial control and 3) time to seizure recurrence. Any child presenting with fever, with asexual forms of Plasmodium falciparum detected in the blood, and without another illness explaining the clinical state was considered to have malaria. Cerebral malaria was defined as a child unable to localize painful stimuli with persistence of coma (Blantyre coma score $\leq$ 2) for more than an hour after control of the seizure, with peripheral parasitaemia and after the exclusion of other causes of encephalopathy, in particular central nervous 
system infections and hypoglycaemia [27]. Seizures were classified as focal, general, or focal with secondary generalization [28].

The Uganda National Council for Science and Technology and the institutional review boards of Makerere University, Kampala and the University of California, San Francisco approved the study.

\section{Data analysis}

Statistical analysis was done using Stata 10.0 (Stata Corp, College Station, TX, USA). Multivariate analysis using logistic regression was used to identify predictors of treatment failure. Associations between potential predictors for treatment failure were assessed using cross-tabulations with chi-squared tests. The final model was selected using the Stata 10.0 backward selection procedure set at $\mathrm{p}<0.20$ and it included: 1) duration of seizures prior to receiving treatment, 2) form of disease (cerebral malaria vs. other forms of severe malaria), 3) seizure type, 4) age and 5) blood sugar level. For survival analysis, differences in survival functions between potential explanatory predictors of seizure recurrence were initially compared using Kaplan Meier curves and the log rank test. The Cox proportional hazard model was applied to assess the independent roles of potential predictors of seizure recurrence. Covariates with a significant $\log$ rank test $(\mathrm{p} \leq$ 0.004 ) were included in the final model. Anti-convulsant treatment received to terminate the seizure was included in both the logistic regression model and Cox model to determine any associations between treatment received and treatment failure or seizure recurrence, respectively. In the Cox model, time analysis was restricted to the first 12 hours after initial control, a period when most (92\%) of the seizures had recurred, and the proportional hazard assumption was not violated.

\section{Results \\ Patient recruitment and baseline characteristics}

Of the 330 patients enrolled in the clinical trial, 221 $(67 \%)$ had malaria and were analysed for outcomes of interest (Figure 1). Of the 221 patients with malaria, 165 $(75 \%)$ had their seizure controlled within 10 minutes of receiving study medications. Of these, six (3\%) patients who received phenorbarbital were excluded from the final analysis. Of the 159 evaluable study patients whose seizures were controlled in the initial 10 minutes, 65 (41\%) experienced a seizure recurrence in the subsequent 24 hours. Of the 221 seizures occurring in malaria patients, 142 (64\%) were associated with a fever, and 48 (22\%) were observed in children diagnosed with cerebral malaria. Characteristics of seizure types in patients who had cerebral malaria and those with other forms of malaria were similar (Table 1). However, patients with cerebral malaria had greater age $(\mathrm{p}<0.001)$ and were more likely to have experienced multiple seizures ( $\mathrm{p}=$ 0.03 ) compared to those who had other types of malaria.

\section{Predictors of treatment failure}

In univariate analysis, the following factors were associated with an increased risk of anti-convulsant treatment failure: focal seizures, cerebral malaria, and blood glucose at presentation $\geq 200 \mathrm{mg} / \mathrm{dl}$ (11 mmol/l) (Table 2). In multivariate analysis, focal seizures, cerebral malaria, and hyperglycaemia remained as significant predictors of anticonvulsant treatment failure (Table 2). In addition, compared to midazolam, diazepam was not associated with a significant risk of treatment failure (OR for failure with diazepam 1.40; 95\% CI 0.77-2.56, $\mathrm{p}=0.26$ ). This was in contrast to the situation in patients who did not have malaria, where diazepam was associated with a significant risk of treatment failure (56\% vs. $26.5 \%$; RR 2.11, 95\% CI $1.26-3.54, \mathrm{p}=0.002$ ) as we reported previously [4].

Predictors of seizure recurrence were also assessed using survival analysis (Figure 2). In addition to focal seizures and cerebral malaria, history of multiple seizures or prior

Table I: Baseline characteristic of patients enrolled in the study

\begin{tabular}{lcc}
\hline Characteristic & Cerebral malaria & Type of malaria \\
Non-cerebral malaria
\end{tabular}

NOTE. All results are medians (IQR) unless otherwise specified. Within 24 hours before enrollment

${ }^{a} \mathrm{p}=0.02$

b $p<0.001$ 


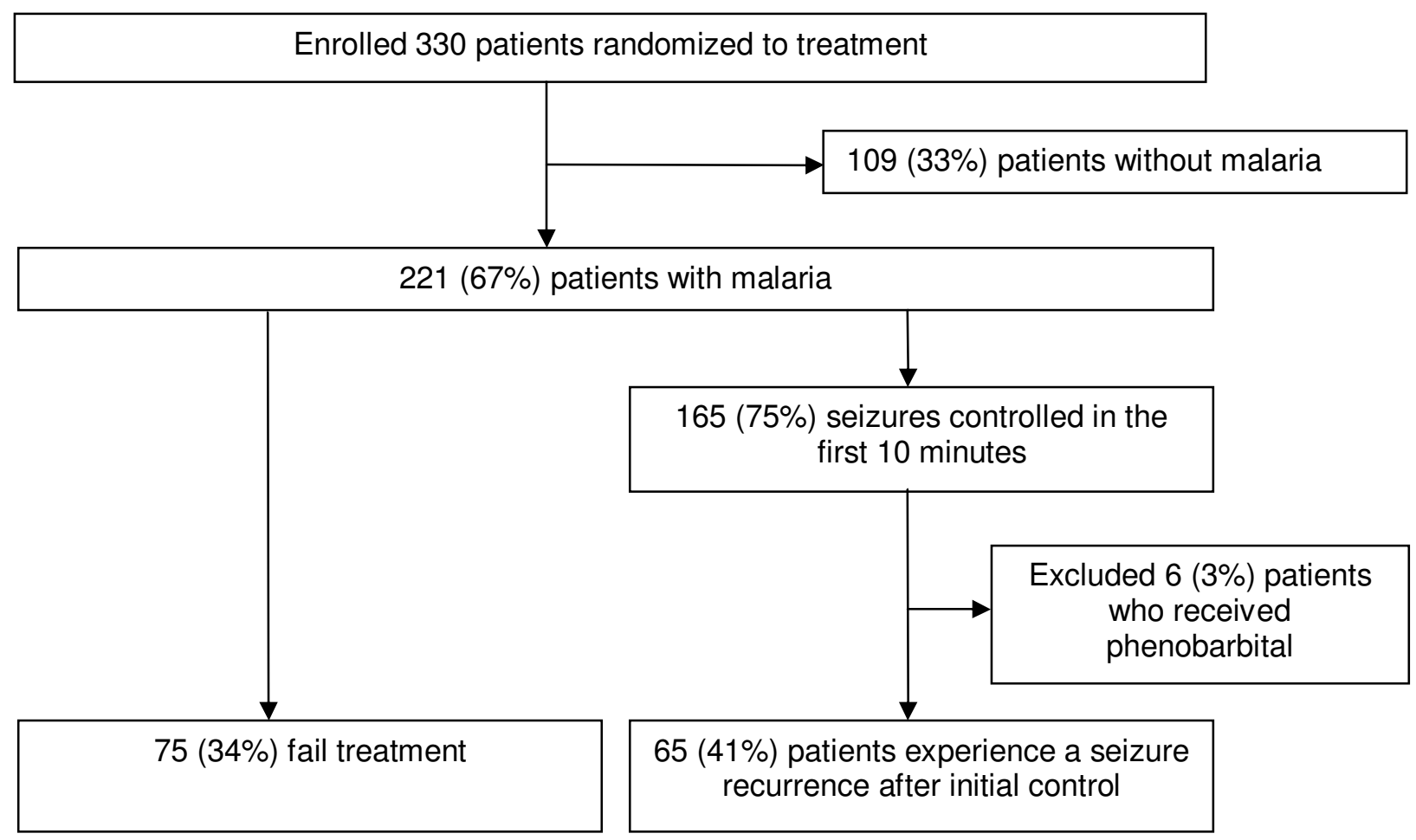

Figure I

Study profile.

use of diazepam was associated with a significant risk of seizure recurrence ( $\mathrm{p} \leq 0.004$ for all comparisons).

In the final Cox proportional hazard model (Table 3), the following factors remained significant predictors of seizure recurrence in the subsequent 12 hours: 1) focal seizures (HR 2.86; 95\%CI 1.49-5.49, p = 0.002), 2) multiple seizures (HR 2.45; 95\%CI 1.42-4.23, $\mathrm{p}=0.001,3$ ) cerebral malaria (HR 3.32; 95\%CI 1.94-5.66, p < 0.001), 4) use of diazepam within 24 hours prior to enrollment in the study (HR $2.4395 \% \mathrm{CI} 1.19-4.95, \mathrm{p}=0.01$ ), and 5) treatment with diazepam to control a seizure (HR 1.96; 95\%CI 1.16-3.33, $\mathrm{p}=0.011$ ).

\section{Discussion}

Predictors of anti-convulsant treatment failure and seizure recurrence were evaluated in Ugandan children presenting to an emergency unit with malaria complicated by prolonged seizures. Presenting with cerebral malaria, focal seizures, or hyperglycaemia were found to be independent predictors of anti-convulsant treatment failure. Predictors of seizure recurrence after initial control with an anticonvulsant included presenting with cerebral malaria, focal seizures, or multiple seizures. In addition, compared to midazolam, prior use of diazepam or initial control of a seizure with diazepam were associated with an increased hazard of experiencing a recurrence. Of note, in children with malaria, focal seizures and cerebral malaria were found to be important markers of refractory seizures, considering that they were associated with both anti-convulsant treatment failure and seizure recurrence.

In this study, children with malaria who presented with focal seizures were more likely to fail treatment than those with other seizure types. This finding is consistent with prior reports that focal seizures are a risk factor for refractory status epilepticus in adults [29]. One possible explanation for this finding is that, in contrast to generalized seizures, focal seizures may be associated with a localized structural injury representative of serious underlying brain pathology. Children presenting with cerebral malaria were also more likely to fail treatment, which is not surprising considering the severe nature of this syndrome [30]. Baseline hyperglycaemia (glucose value $\geq 200 \mathrm{mg} /$ dl) $(11 \mathrm{mmol} / \mathrm{l})$ was found to be a risk factor for treatment failure. Stress hyperglycaemia, a known complication in critically ill children, has been associated with increased mortality [31-33]. It is possible that, in children with severe malaria, hyperglycaemia is a surrogate marker of ongoing serious brain disease [33]. As previously 
Table 2: Univariate and multivariate analysis for factors predicting treatment failure

\begin{tabular}{|c|c|c|c|c|c|c|c|}
\hline \multirow[b]{2}{*}{ Variable } & \multirow[b]{2}{*}{ Number of treatment failures } & \multicolumn{3}{|c|}{ Univariate } & \multicolumn{3}{|c|}{ Multivariate } \\
\hline & & Odds ratio & $95 \% \mathrm{Cl}$ & p-value & Odds ratio & $95 \% \mathrm{Cl}$ & p-value \\
\hline \multicolumn{8}{|l|}{ Type of seizure } \\
\hline Generalized seizure & 56 & - & - & & 1 & - & - \\
\hline Focal seizure & 19 & 3.47 & $1.57-7.67$ & $<0.001$ & 3.21 & $1.42-7.25$ & 0.005 \\
\hline \multicolumn{8}{|l|}{ Form of disease } \\
\hline Non-cerebral malaria & 52 & - & - & & 1 & - & - \\
\hline Cerebral malaria & 23 & 2.14 & $1.10-4.15$ & 0.02 & 2.43 & $|.20-4.9|$ & 0.01 \\
\hline \multicolumn{8}{|c|}{ Recent use of diazepam } \\
\hline No & 65 & - & - & & a & & \\
\hline Yes & 10 & 1.88 & $0.75-4.70$ & 0.16 & a & & \\
\hline \multicolumn{8}{|c|}{$\begin{array}{l}\text { Pre-treatment blood glucose } \\
\text { level }\end{array}$} \\
\hline$<200 \mathrm{mg} / \mathrm{dl}$ & 62 & 1 & - & & 1 & & \\
\hline$\geq 200 \mathrm{mg} / \mathrm{dl}$ & 13 & 2.85 & $1.16-6.95$ & 0.01 & 2.84 & $1.11-7.20$ & 0.02 \\
\hline \multicolumn{8}{|l|}{ Age } \\
\hline$>\mathrm{II}$ months & 54 & I & - & & 1 & & \\
\hline$<12$ months & 21 & 1.88 & $0.96-3.67$ & 0.06 & 1.99 & $0.96-4.13$ & 0.06 \\
\hline \multicolumn{8}{|l|}{ Number of seizures } \\
\hline$<3$ & 38 & 1 & - & & a & & \\
\hline$\geq 3$ & 37 & 1.18 & $0.80-2.56$ & 0.21 & a & & \\
\hline \multicolumn{8}{|l|}{ Treatment received } \\
\hline Midazolam & 37 & I & - & & 1 & & \\
\hline Diazepam & 38 & 1.21 & $0.69-2.11$ & 0.50 & 1.40 & $0.77-2.56$ & 0.26 \\
\hline \multicolumn{8}{|c|}{$\begin{array}{l}\text { Unconscious prior to onset of } \\
\text { seizure }\end{array}$} \\
\hline No & 35 & I & - & & a & & \\
\hline Yes & 37 & 1.60 & $0.90-2.85$ & 0.11 & a & & \\
\hline
\end{tabular}

a Not included in the final model.

reported, considering all children with prolonged seizures, diazepam was associated with a significant risk of treatment failure compared to midazolam [4]. Considering the impact of malaria, children with prolonged seizures and malaria who received diazepam, but not those who received midazolam, were less likely to fail treatment compared to those without malaria [4]. This finding of decreased failures of diazepam in children with malaria contrasts with findings of another recent trial [34], perhaps due to differences in study design.

Risk factors for seizure recurrence in children with malaria have not been well characterized. Predictors of seizure recurrence in patients without malaria include presentation with multiple or focal seizures [35]. In this study of children with malaria, focal seizures, cerebral malaria, and presenting with multiple seizures were all independent risk factors for seizure recurrence. In addition, seizures that were controlled with diazepam were significantly more likely to recur in the subsequent 12 hours as compared to those controlled by midazolam. This finding suggests that, in the absence of alternative anti-convulsants, diazepam is likely to be administered repeatedly, exposing patients to the risk of drug induced respiratory depres- sion $[15,27]$, a complication that may commonly be fatal in rural sub-Saharan Africa, where assisted ventilation is generally unavailable $[6,16]$. In addition, diazepam induced respiratory depression may increase mortality in children with severe malaria by suppressing control of metabolic acidosis and/or increased intracranial pressure $[16,13,14,17]$.

These predictors can be used to identify children with malaria who may benefit from alternative therapy, in the particular the use of longer-acting and safer acting anticonvulsants, such as midazolam or lorazepam. More studies are urgently needed to evaluate the effectiveness and prophylactic benefit of longer acting agents in the treatment of seizures in children with malaria.

\section{Conflict of interests}

The authors declare that they have no competing interests. The sponsors of this study and the donors of study drugs had no role in study design, the collection, analysis, or interpretation of data or in the writing of this report. 

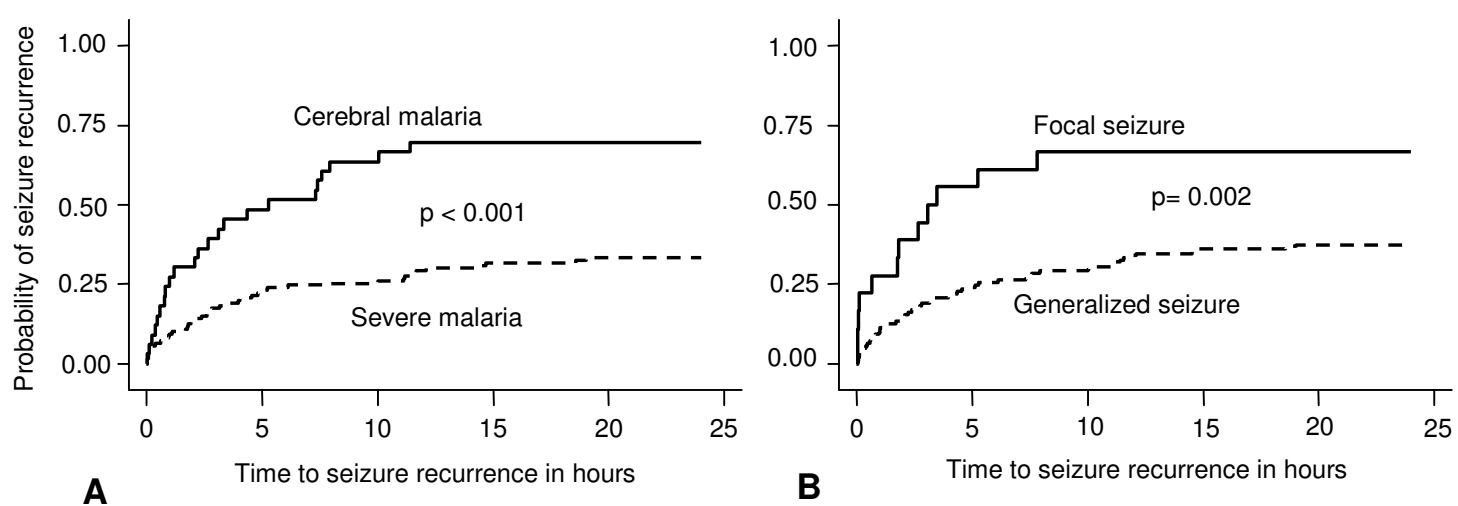

\section{Number at risk}

Non cerebral malaria
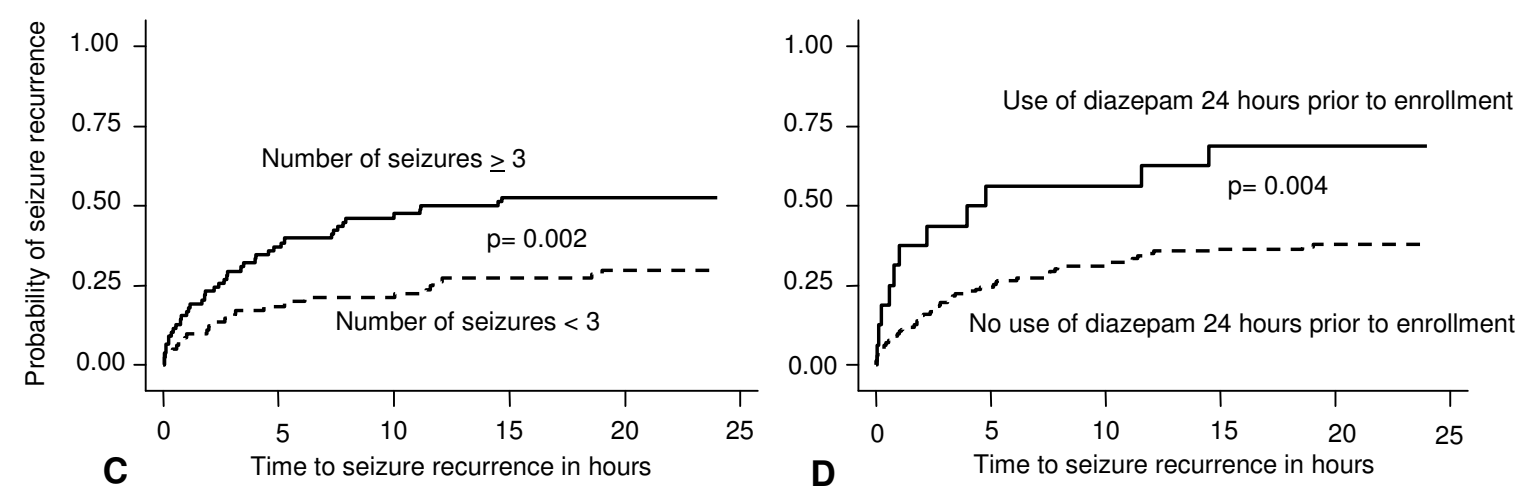

Number at risk

Number at risk

Number of seizures $<3 \quad-81 \quad 66 \quad 64 \quad 59$

$\begin{array}{llllll}\text { Number of seizures }>2 & 78 & 49 & 42 & 37\end{array}$

\section{Figure 2}

Kaplan-Meier plots of time to first seizure recurrence within $\mathbf{2 4}$ hours after initial control for the subgroups indicated. Figure 2 shows Kaplan Meier survival plots showing time to seizure recurrence within 24 hours after initial control of the seizure in the following subgroups of patients: A. Malaria type: Cerebral malaria vs. non-cerebral malaria. B. Seizure type: Focal seizures vs. generalized seizures. C. Seizure frequency *: $>2$ vs. < 3. D. Prior treatment with diazepam*: Received diazepam vs. did not receive diazepam. $* 24$ hours prior to presentation to the acute care unit.

Table 3: Cox model for predictors of seizure recurrence within $\mathbf{2}$ hours after initial control

\begin{tabular}{|c|c|c|c|}
\hline Characteristic & Hazard ratio & $95 \% \mathrm{Cl}$ & p-value \\
\hline Focal seizure & 2.86 & I.49-5.49 & 0.002 \\
\hline Number of seizures prior to treatment: $\geq 3$ & 2.45 & $1.42-4.23$ & 0.001 \\
\hline Cerebral malaria & 3.32 & $1.94-5.66$ & $<0.001$ \\
\hline Recent use of diazepam & 2.43 & $1.19-4.95$ & 0.01 \\
\hline Treatment with diazepam vs. midazolam & 1.96 & $1.16-3.33$ & 0.01 \\
\hline
\end{tabular}




\section{Authors' contributions}

AM contributed to study design and coordination, collected data, supervised patient enrollment and follow-up, and analyzed and interpreted data. JB contributed to study design, supervised coordination of the study, enrollment, and clinical care of the patients and contributed to interpretation of data. GN contributed to study design and coordination, supervised enrollment and follow-up of the patients and contributed to data interpretation. SS contributed to study design, analysis and data interpretation. PJR contributed to study design and coordination, analysis and data interpretation. All authors read and approved the final manuscript.

\section{PJR is a Doris Duke Charitable Foundation Distinguished} Clinical Scientist.

\section{Acknowledgements}

Both study drugs were donated by Roche Products Limited, Nairobi, Kenya. We thank the study clinical team (Aggrey Dhabangi, Jolly Rubambarama, Julian Eyotaru, Florence Pido, Rose Nakikwaku, and Maria Rutaro) and laboratory team (Maxwell Kilama, Regina Nakafeero and Felix Jurua). We also thank Grant Dorsey for providing methodological and statistical guidance, Professor Richard Odome Odoi, Paul Musoke and Benjamin Mwesigwe, who designed and prepared the placebos used in the study, and the children and families who participated in this study.

\section{Financial disclosure}

This investigation received support from the Fogarty International Center of the National Institutes of Health (D43 TWOI506) and the Nuffield Foundation.

\section{References}

I. Waruiru CM, Newton CR, Forster D, New L, Winstanley P, Mwang I, Marsh V, Winstanley M, Snow RW, Marsh K: Epileptic seizures and malaria in Kenyan children. Trans R Soc Trop Med Hyg 1996, 90:152-155.

2. Iloeje SO: Paediatric neurologic emergencies at the University of Nigeria Teaching Hospital, Enugu. West Afr J Med 1997 16:80-84.

3. Idro R, Ndiritu M, Ogutu B, Mithwani S, Maitland K, Berkley J, Crawley J, Fegan G, Bauni E, Peshu N, Marsh K, Neville B, Newton C: Burden, features, and outcome of neurological involvement in acute falciparum malaria in Kenyan children. Jama 2007, 297:2232-2240.

4. Mpimbaza A, Ndeezi G, Staedke S, Rosenthal PJ, Byarugaba J: Comparison of buccal midazolam with rectal diazepam in the treatment of prolonged seizures in Ugandan children: a randomized clinical trial. Pediatrics 2008, I 2 I:e58-64.

5. Idro R, Gwer S, Kahindi M, Gatakaa H, Kazungu T, Ndiritu M, Maitland K, Neville BG, Kager PA, Newton CR: The incidence, aetiology and outcome of acute seizures in children admitted to a rural Kenyan district hospital. BMC Pediatr 2008, 8:5.

6. Idro R, Aketch S, Gwer S, Newton CR, Maitland K: Research priorities in the management of severe Plasmodium falciparum malaria in children. Ann Trop Med Parasitol 2006, 100:95-108.

7. Molyneux ME, Taylor TE, Wirima JJ, Borgstein A: Clinical features and prognostic indicators in paediatric cerebral malaria: a study of I3 I comatose Malawian children. Q J Med 1989, 7l:44I-459.

8. Bondi FS: The incidence and outcome of neurological abnormalities in childhood cerebral malaria: a long-term follow-up of 62 survivors. Trans $R$ Soc Trop Med Hyg 1992, 86: I7-19.

9. Brewster DR, Kwiatkowski D, White NJ: Neurological sequelae of cerebral malaria in children. Lancet 1990, 336:039-1043.
10. Boivin MJ, Bangirana P, Byarugaba J, Opoka RO, Idro R, Jurek AM, John CC: Cognitive impairment after cerebral malaria in children: a prospective study. Pediatrics 2007, I I 9:e360-366.

II. Carter JA, Neville BG, White S, Ross AJ, Otieno G, Mturi N, Musumba $C$, Newton CR: Increased prevalence of epilepsy associated with severe falciparum malaria in children. Epilepsia 2004, 45:978-98I.

12. Severe falciparum malaria. World Health Organization, Communicable Diseases Cluster. Trans $R$ Soc Trop Med Hyg 2000, 94(SuppI I):SI-90.

13. Ogutu BR, Newton CR, Crawley J, Muchohi SN, Otieno GO, Edwards G, Marsh K, Kokwaro GO: Pharmacokinetics and anticonvulsant effects of diazepam in children with severe falciparum malaria and convulsions. Br J Clin Pharmacol 2002, 53:49-57.

14. Maitland K, Marsh K: Pathophysiology of severe malaria in children. Acta Trop 2004, 90: | 31-| 40.

I5. Scott RC, Neville BG: Pharmacological management of convulsive status epilepticus in children. Dev Med Child Neurol 1999 , 41:207-210.

16. Norris E, Marzouk O, Nunn A, Mclntyre J, Choonara I: Respiratory depression in children receiving diazepam for acute seizures: a prospective study. Dev Med Child Neurol 1999, 41:340-343.

17. Crawley J, Waruiru C, Mithwani S, Mwangi I, Watkins W, Ouma D, Winstanley P, Peto T, Marsh K: Effect of phenobarbital on seizure frequency and mortality in childhood cerebral malaria: a randomised, controlled intervention study. Lancet 2000, 355:701-706.

18. Wallace SJ: Nasal benzodiazepines for management of acute childhood seizures? Lancet 1997, 349:222.

19. Griffith N, Howell S, Mason DG: Intranasal midazolam for premedication of children undergoing day-case anaesthesia: comparison of two delivery systems with assessment of intra-observer variability. Br J Anaesth 1998, 8 I:865-869.

20. Scott RC, Besag FM, Neville BG: Buccal midazolam and rectal diazepam for treatment of prolonged seizures in childhood and adolescence: a randomised trial. Lancet I999, 353:623-626.

21. Lahat E, Goldman M, Barr J, Bistritzer T, Berkovitch M: Comparison of intranasal midazolam with intravenous diazepam for treating febrile seizures in children: prospective randomised study. BMJ 2000, 32 1:83-86.

22. Baysun S, Aydin OF, Atmaca E, Gurer YK: A comparison of buccal midazolam and rectal diazepam for the acute treatment of seizures. Clin Pediatr (Phila) 2005, 44:771-776.

23. Mclntyre J, Robertson S, Norris E, Appleton R, Whitehouse WP, Phillips B, Martland T, Berry K, Collier J, Smith S, Choonara I: Safety and efficacy of buccal midazolam versus rectal diazepam for emergency treatment of seizures in children: a randomised controlled trial. Lancet 2005, 366:205-210.

24. Pramar YV, Loucas VA, el-Rachidi A: Stability of midazolam hydrochloride in syringes and i.v. fluids. Am J Health Syst Pharm 1997, 54:913-915.

25. Smith FM, Nuessle NO: Stability of diazepam injection repackaged in glass unit-dose syringes. Am J Hosp Pharm 1982, 39: 1687-1690.

26. Gottwald MD, Akers LC, Liu PK, Orsulak PJ, Corry MD, Bacchetti P, Fields SM, Lowenstein DH, Alldredge BK: Prehospital stability of diazepam and lorazepam. Am J Emerg Med 1999, I 7:333-337.

27. Newton CR, Taylor TE, Whitten RO: Pathophysiology of fatal falciparum malaria in African children. Am J Trop Med Hyg 1998, 58:673-683.

28. Riviello JJ Jr, Ashwal S, Hirtz D, Glauser T, Ballaban-Gil K, Kelley K, Morton LD, Phillips S, Sloan E, Shinnar S: Practice parameter: diagnostic assessment of the child with status epilepticus (an evidence-based review): report of the Quality Standards Subcommittee of the American Academy of Neurology and the Practice Committee of the Child Neurology Society. Neurology 2006, 67:1542-1550.

29. Mayer SA, Claassen J, Lokin J, Mendelsohn F, Dennis LJ, Fitzsimmons BF: Refractory status epilepticus: frequency, risk factors, and impact on outcome. Arch Neurol 2002, 59:205-210.

30. Wattanagoon Y, Srivilairit S, Looareesuwan S, White NJ: Convulsions in childhood malaria. Trans $R$ Soc Trop Med Hyg 1994, 88:426-428

31. Osier FH, Berkley JA, Ross A, Sanderson F, Mohammed S, Newton $\mathrm{CR}$ : Abnormal blood glucose concentrations on admission to 
a rural Kenyan district hospital: prevalence and outcome. Arch Dis Child 2003, 88:62I-625.

32. Srinivasan V, Spinella PC, Drott HR, Roth CL, Helfaer MA, Nadkarni $\mathrm{V}$ : Association of timing, duration, and intensity of hyperglycemia with intensive care unit mortality in critically ill children. Pediatr Crit Care Med 2004, 5:329-336.

33. Kong MY, Alten J, Tofil N: Is hyperglycemia really harmful? A critical appraisal of "Persistent hyperglycemia in critically ill children" by Faustino and Apkon (J Pediatr 2005; 146:30-34). Pediatr Crit Care Med 2007, 8:482-485.

34. Ikumi ML, Muchohi SN, Ohuma EO, Kokwaro GO, Newton CR: Response to diazepam in children with malaria induced seizures. Epilepsy Res 2008, 82:215-218.

35. Sogawa $Y$, Maytal J: Emergency department admission of children with unprovoked seizure: recurrence within 24 hours. Pediatr Neurol 2006, 35:98-10I.

Publish with Bio Med Central and every scientist can read your work free of charge

"BioMed Central will be the most significant development for disseminating the results of biomedical research in our lifetime. "

Sir Paul Nurse, Cancer Research UK

Your research papers will be:

- available free of charge to the entire biomedical community

- peer reviewed and published immediately upon acceptance

- cited in PubMed and archived on PubMed Central

- yours - you keep the copyright

Submit your manuscript here:

http://www.biomedcentral.com/info/publishing_adv.asp 